\title{
Screening of tomato landraces for drought tolerance based on growth and chlorophyll fluorescence analyses
}

\author{
Naeimeh Sousaraei ${ }^{1} \cdot K$ Kambiz Mashayekhi ${ }^{1}$ Seyyed Javad Mousavizadeh ${ }^{1} \cdot$ Vahid Akbarpour $^{2} \cdot$ Joaquín Medina $^{3}$. \\ Sasan Aliniaeifard ${ }^{4}$
}

Received: 7 October 2020 / Revised: 3 December 2020 / Accepted: 8 December 2020 / Published online: 5 March 2021

(c) The Author(s) 2021

\begin{abstract}
To investigate the effects of water withholding on 17 tomato (Solanum lycopersicum L.) landraces collected from different climatic zones of Iran and two commercial hybrids, the polyphasic OJIP fluorescence transient, relative water content (RWC), electrolyte leakage (EL) and vegetative growth parameters were analyzed. Duncan's multiple range test (DMRT) for all the studied parameters and drought factor index (DFI) based on performance index on the absorption basis $\left(\mathrm{PI}_{\mathrm{abs}}\right)$ were used for screening the plants based on their tolerance to drought condition. Result showed that compared to the control plants, vegetative growth parameters, $\mathrm{RWC}, \mathrm{PI}_{\mathrm{abs}}$, relative maximal variable fluorescence $\left(\mathrm{F}_{\mathrm{M}} / \mathrm{F}_{0}\right)$, maximum quantum efficiency of PSII $\left(\mathrm{F}_{\mathrm{V}} / \mathrm{F}_{\mathrm{M}}\right)$, quantum yield of electron transport $\left(\Phi \mathrm{E}_{0}\right)$ and electron transport flux per reaction center $(\mathrm{RC})\left(\mathrm{ET}_{0} / \mathrm{RC}\right)$ were decreased, whereas, EL, quantum yield of energy dissipation $\left(\Phi \mathrm{D}_{0}\right)$, specific energy fluxes per RC for energy absorption $(\mathrm{ABS} / \mathrm{RC})$ and dissipated energy flux $\left(\mathrm{DI}_{0} / \mathrm{RC}\right)$, which are closely related to the incidence of photoinhibition were increased in plants exposed to water withholding. DMRT and DFI screening results clearly categorized the landraces into three groups (tolerant, moderately sensitive and sensitive). Tolerant landraces showed less change for most of the measured parameters compared to sensitive and moderately sensitive landraces. We found that adapted landraces to dry climates had a higher

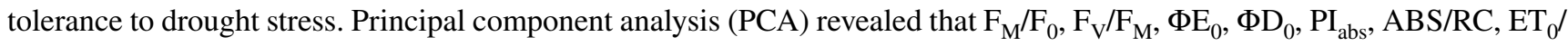
$\mathrm{RC}$ and $\mathrm{DI}_{0} / \mathrm{RC}$ parameters are the most sensitive parameters for detection of impact of drought stress on tomato plants. In conclusion, the eight parameters have the potential to identify the drought injury in tomato seedlings.
\end{abstract}

Keywords Duncan's multiple range test · OJIP-test $\cdot$ Photosynthesis $\cdot$ Untapped genetic resources $\cdot$ Water stress

\section{Introduction}

Communicated by Sung-Chur Sim.

Kambiz Mashayekhi

Kkmabizmashayekhi@gmail.com

Sasan Aliniaeifard

aliniaeifard@ut.ac.ir

1 Department of Horticultural Sciences, Gorgan University of Agricultural Sciences and Natural Resources, Gorgān, Iran

2 Department of Horticultural Sciences, Sari Agricultural Sciences and Natural Resources University, Sari, Iran

3 Department of Biotechnology, Instituto Nacional de Investigación y Tecnología Agraria y Alimentaria (INIA), Crta de la Coruña km7.5, 28040 Madrid, Spain

4 Photosynthesis Laboratory, Department of Horticultural Sciences, Aburaihan Campus, University of Tehran, Tehran, Iran
Tomato (Solanum lycopersicum L.), with annual global production of around 182.3 million tons, is the second top tonnage produced vegetable worldwide (FAOSTAT 2018). Tomato is not categorized as a tolerant plant in response to many abiotic stress conditions and its growth and productivity is limited by unfavorable environmental conditions such as drought and salinity (Dong et al. 2020). Drought stress has diverse negative effects on tomato during its ontogeny (Jiang et al. 2019). In general plant susceptibility to drought depends on the genotype, timing and intensity of the imposed stress (Aliniaeifard and Van Meeteren 2016a, b).

Drought stress causes many adverse effects including negative leaf water balance, turgor loss, chlorophyll (Chl) degradation and down-regulation of photosynthesis through affecting stomatal functioning and restricting supply of carbon dioxide (Zhou et al. 2017). Cell enlargement, leaf 
expansion, root and shoot development, dry matter partitioning and consequently yield are also negatively influenced by drought stress (Farooq et al. 2009). Up to the present a great number of investigations have been conducted to develop strategies to help plants to cope with drought stress (Aliniaeifard and Van Meeteren 2016a, b; Lastochkina et al. 2019; Khan et al. 2020).

Realization and reflection on the value contained in the biodiversity and the genetic treasure available in exotic and wild species provide possibilities to select tolerant plants capable to cope with environmental stresses (De Almeida Cançado 2011). Landraces are one of the most important components of plant genetic resource. Tomato landraces are still cultivated for local use and consumption in different areas of the world (Lázaro 2018). The main contribution of landraces in plant breeding programs is their potential to adapt in stressful conditions. Therefore, utilization of landraces that are tolerant to abiotic stresses is a promising approach to alleviate the negative effects of stresses and to increase water use efficiency and crop production in vulnerable areas (Henareh et al. 2015).

To reach to a drought-tolerant crop, using the natural patterns of diversity will facilitate identifying drought tolerance in a large numbers of landraces in a short time. This improves productivity and stability of plants in regions that frequently experiencing drought (Gupta et al. 2020). There are various methods to study large-scale patterns of distribution and diversity of landraces to characterize their behavior in stressful and normal environments as well as to screen drought tolerant landraces (Adhikari et al. 2009; Cabello et al. 2012, 2013). Among them, Chl fluorescence measurement as a non-destructive, simple, rapid and highly sensitive method is potentially capable of monitoring and screening of a diverse population of plants (Chaerle et al. 2007). Here, we have focused on the Chl fluorescence measurement for screening the drought tolerant tomato landraces. Once, darkadapted leaves are illuminated with continuous light, Chl fluorescence exhibits the characteristic changes in the intensity accompanying with induction of photosynthetic activity (Poudyal et al. 2019). Fluorescence emission increases under stress conditions and its intensity generally being inversely correlated with photosynthetic efficiency. Almost all changes in composition and function of the photosynthetic components including energy trapping, electron transport and dissipation of excitation energy in the antenna complex and some others can be reflected by Chl fluorescence (Çiçek et al. 2020). Chl fluorescence kinetics substantially impresses under stress conditions. This may confirm the possibility of using $\mathrm{Chl}$ fluorescence technology as a probe for detecting the healthiness of photosynthetic machinery and the mechanism of plant stress responses (Boureima et al. 2012).

There is a computational tool to analyze the fast $\mathrm{Chl}$ fluorescence induction curves in view of the various photosystem II (PSII) reactions, based on energy fluxes, known as OJIP test (Jedmowski and Brüggemann 2015). The OJIP test is applied to interpret several biophysical phenomenological and expressions that quantify PSII situation (Küpper et al. 2019).

This technique has been applied with success in the recent years to evaluate PSII status and screening several plant species for abiotic stress tolerance. For instance, Boureima et al. (2012) used Chl fluorescence imaging system and OJIP-test to screen sesame (Sesamum indicum) mutant germplasm under drought stress, they expressed a Drought Factor Index (DFI), a parameter calculated from Performance Index (PI), which is able to appraise the response of the mutants to drought stress and to rank them according to drought stress tolerance. They detected large genotypic variation in 24 sesame genotypes by the measurement of OJIP fluorescence transients. Jedmowski and Brüggemann (2015) applied imaging of parameters of the fast $\mathrm{Chl}$ fluorescence induction (OJIP) kinetic of 20 genotypes of wild barley (Hordeum spontaneum) at the influence of heat stress on PSII. They also quantified the impact of heat stress by estimating a Heat Resistance Index (HRI), derived from the decrease of the PI caused by stress and following recovery. Their results proved that OJIP-test parameters could be considered for screening and phenotyping studies aiming to characterize plant genotypes.

Poudyal et al. (2019) screened tomato lines for heat tolerance by measuring maximum quantum efficiency of PSII $\left(\mathrm{F}_{\mathrm{V}} / \mathrm{F}_{\mathrm{M}}\right.$ or $\left.\Phi \mathrm{P}_{0}\right)$ and used this biophysical parameter for selecting sensitive (low $\mathrm{F}_{\mathrm{V}} / \mathrm{F}_{\mathrm{M}}$ ) and tolerant (high $\mathrm{F}_{\mathrm{V}} / \mathrm{F}_{\mathrm{M}}$ ) cultivars to investigate high fruit yield during thermal stress in the field. They proposed that $\mathrm{F}_{\mathrm{V}} / \mathrm{F}_{\mathrm{M}}$ parameter is enough effective for detection and screening seedlings for heat sensitivity and can speed up the time needed for crop improvement. Dong et al. (2020) used Chl fluorescence imaging system as a tool for analyzing the effects of chilling injury on tomato seedling leaves. Their results revealed that six fluorescence parameter values of $\mathrm{F}_{\mathrm{V}} / \mathrm{F}_{\mathrm{M}}$, PSII actual photochemical quantum yields [Y(II)], photochemical quenching coefficient (qP), photochemical quenching coefficient (qL), Quantum yield of non-regulated energy dissipation in PSII [Y(NO)] and Quantum yield of regulated energy dissipation in PSII [Y(NPQ)] can be used to identify cold sensitivity of tomato seedlings. Chl fluorescence technique (under non-photorespiratory conditions) has been largely used for tracking stomatal behavior when the leaves are exposed to drought or Abscisic acid (ABA) as well (Aliniaeifard et al. 2014; Aliniaeifard and van Meeteren 2014, 2016a; van Meeteren et al. 2020).

In this research, seeds of 17 tomato landraces of different climatic zones of Iran ( 2 very wet, 4 wet, 5 semiarid, 5 dry, and one ultra-dry) and two popular tomato hybrids were evaluated for drought tolerance. Measurements of Chl 
$a$ fluorescence, vegetative growth parameters, relative water content (RWC), and electrolyte leakage were carried out. We have used two methods for screening: (1) Screening by the Duncan's multiple range test (DMRT) (2) Screening by the drought factor index (DFI). We hypothesized that these methods are able to rank the landraces according to their sensitivity/tolerance against drought stress. We also applied principle component analysis (PCA) for discovering the parameters that had the greatest impact on screening.

\section{Material and methods}

\subsection{Plant material and growth conditions}

Seventeen tomato landraces of Iran (Supplementary Fig. S1; Table 1) and two commercial hybrids (Matin and 8320) were used to assess their tolerance to drought stress. Seeds of the tomato landraces and the cultivars were sown in plug trays filled with cocopeat: perlite (2:1) substrate in the greenhouse. After two weeks, the seedlings were transferred to $12 \mathrm{~cm}$ plastic pots containing cocopeat: soil: perlite $(1: 2: 1)$ substrate. The plants were grown in a greenhouse under $14 / 10 \mathrm{~h} \mathrm{light/dark}$ condition at an average temperature of $26 / 22{ }^{\circ} \mathrm{C}$ day/night and $50 \%$ of relative humidity. The plants were irrigated twice per week with water and once with half-strength Hoagland solution. In the five-leaf stage,

Table 1 Location, average temperature $\left({ }^{\circ} \mathrm{C}\right)$ and total annual rainfall (mm/year) of seventeen different geographical areas of Iran where local landraces were obtained (Iran Meteorological Organization 2019)

\begin{tabular}{llll}
\hline Number & Location & $\begin{array}{l}\text { Average tem- } \\
\text { perature }\left({ }^{\circ} \mathrm{C}\right)\end{array}$ & $\begin{array}{l}\text { Total annual } \\
\text { rainfall }(\mathrm{mm} / \\
\text { year})\end{array}$ \\
\hline 1 & Zanjan & 11.28 & 295.4054 \\
2 & Kordestan & 13.8 & 675.8 \\
3 & Varamin & 18 & 151.7 \\
4 & Rasht & 16.5 & 1346 \\
5 & Shahroud & 12.3 & 233.3 \\
6 & Hamedan & 11.95 & 308.4054 \\
7 & Sirjan & 21 & 135 \\
8 & Esfarayen & 16.5 & 300.5 \\
9 & Yazd & 19.92 & 55 \\
10 & Gorgan & 18.4 & 502.9 \\
11 & Shiraz & 18.4 & 316.8 \\
12 & Semnan & 17.1 & 140 \\
13 & Sari & 18.2 & 764.9 \\
14 & Kermanshah & 15.1 & 423.6216 \\
15 & Neishabour & 14.3 & 231 \\
16 & Orumie & 11.47 & 314.5946 \\
17 & Bandar-Torkman & 17.7 & 462.3 \\
\hline
\end{tabular}

plants were divided into two groups, half of them were normally irrigated (control) and for the other half, watering was stopped (drought-stressed plants) for duration of one week. In a same time of water withholding in drought-stressed plants, the control plants were well-watered every two day.

\subsection{Measurements of growth parameters}

One week following water withholding, growth and morphological characteristics such as height, leaf number, shoot dry weight $\left(\mathrm{DW}_{\text {Shoot }}\right)$, root volume $\left(\mathrm{V}_{\text {Root }}\right)$, root fresh weight $\left(\mathrm{FW}_{\text {Root }}\right)$, root dry weight $\left(\mathrm{DW}_{\text {Root }}\right)$ from stressed and nonstressed plants were measured. To measure dry weight, the samples were dried in an air-forced oven for $24 \mathrm{~h}$ at $75^{\circ} \mathrm{C}$. Root parameters were calculated using GiaRoot software based on the method described by Galkovskyi et al. (2012).

\subsection{Chlorophyll (Chl) a fluorescence measurements}

Third young fully developed tomato leaves were used for analyzing their Chl $a$ fluorescence based on the method described by Seifikalhor et al. (2019). Selected leaves were dark-adapted prior to the measurements and OJIP protocol was applied using a fluorometer (FluorPen FP 100-MAX, photon system instruments, Drasov, Czech Republic). The fluorescence measurement was performed using a saturating light of $3900 \mu \mathrm{mol} \mathrm{m}^{-2} \mathrm{~s}^{-1}$. FluorPen software was used to extract data from the original measurement. Data extracted were used to analyze the following data according to the equations of the JIP test (Strasser et al., 2000): fluorescence intensities at $50 \mu \mathrm{s}\left(\mathrm{F} 50 \mu \mathrm{s}\right.$, considered as the $\left.\mathrm{F}_{0}\right), 2 \mathrm{~ms}$ (J-step denoted as $\mathrm{F}_{\mathrm{J}}$ ), $60 \mathrm{~ms}$ (I-step, $\mathrm{F}_{\mathrm{I}}$ ), and maximum fluorescence intensity $\left(\mathrm{F}_{\mathrm{M}}, \mathrm{F}_{\mathrm{P}}\right)$. The JIP-test was used to quantify the amount of energy that flow via the PSII (Strauss et al. 2006).

Performance index was measured on the absorption basis ( $\mathrm{PI}_{\mathrm{abs}}$, a multi-parametric expression). Probability that a trapped exaction promote an electron in electron transport chain (ETC) beyond the primary acceptor Quinone $\left(\mathrm{Q}^{\mathrm{A}-}\right)$ $\left(\Psi_{0}\right)$, maximum quantum efficiency of PSII $\left(\mathrm{F}_{\mathrm{V}} / \mathrm{F}_{\mathrm{M}}\right)$, quantum yield of electron transport $\left(\Phi \mathrm{E}_{0}\right)$, quantum yield of energy dissipation $\left(\Phi \mathrm{D}_{0}\right)$, specific energy fluxes per reaction center (RC) for energy absorption (ABS/RC), trapped energy flux $\left(\mathrm{TR}_{0} / \mathrm{RC}\right)$, electron transport flux $\left(\mathrm{ET}_{0} / \mathrm{RC}\right)$ and dissipated energy flux $\left(\mathrm{DI}_{0} / \mathrm{RC}\right)$ were calculated according to Kalhor et al. (2018).

\subsection{Measurements of relative water content (RWC) and electrolyte leakage (EL)}

To measure the RWC, 10 leaf discs $(0.5 \mathrm{~cm}$ diameter $)$ sample from the selected young fully developed leaves were taken using cork-borer weighed immediately to determine the 
fresh weight $(\mathrm{FW})$ and transferred to tubes containing $10 \mathrm{ml}$ of distilled water. After $24 \mathrm{~h}$, the weight of leaf samples was recorded to determine their turgid weight (TW). Each sample was placed in a paper bag and dried in an air-forced oven at $70{ }^{\circ} \mathrm{C}$ for $48 \mathrm{~h}$. The dried samples were weighed to determine the dry weight (DW). RWC was calculated using the following equation (Gindaba et al. 2004):

$R W C=\frac{F W-D W}{T W-D W} \times 100$

Electrolyte leakage (EL) was measured for the estimation of cell membrane stability in plants. placed in closed vials containing, 10 leaf discs ( $0.5 \mathrm{~cm}$ diameter) sample from the young fully developed leaf was taken using a cork borer and washed with deionized water to remove surface-adhered electrolytes, and immersed in $10 \mathrm{~mL}$ deionized water at room temperature for $24 \mathrm{~h}$. Then, the electrical conductivity (EC) of the samples was recorded as primary leakage (PL) and after one hour boiling of the samples in a bain-marie $\left(100{ }^{\circ} \mathrm{C}\right)$ the secondary leakage (SL) was recorded. Electrolyte leakage was calculated using the following equation (Shiferaw and Baker 1996):

$E L=1-\left(\frac{P L}{S L}\right) * 100$.

\subsection{Screening methods}

Two methods were used for monitoring and screening the plants based on their tolerance to drought condition: (1) Duncan's multiple range test (DMRT) for all the studied parameters, (2) drought factor index (DFI) based on $\mathrm{PI}_{\mathrm{abs}}$.

\subsubsection{Screening based on the Duncan's multiple range test (DMRT)}

After measuring all traits, the relative value of traits [(value of trait stressed $_{\text {/value of trait }}$ non-stressed $) \times 100$ ] for each landrace was calculated. Analysis of variance (ANOVA) and Duncan's multiple range test (DMRT) were carried out in order to compare the drought tolerance of the landraces. As it is well known, the results of DMRT will be shown in a table with different columns from highest to lowest means. In this study, means define the ratio between stressed and nonstressed plants. These differences assigned by letters namely $\underline{a}, \underline{a b}, \underline{b}$ and etc. The landraces grouped in the same column do not show a significant difference as assigned by the same letters.

In sake of ranking the landraces, scoring was performed based on the letters of the Duncan test according to Kafi et al. (2005). As can be clearly seen from Table 2, the scores $\mathbf{1}, \mathbf{1 . 5}$ and $\mathbf{1 . 6 6}$ in turn come from $\underline{a}, \underline{a b}, \underline{a b c}$ letters. For other letters, the scoring can be followed in Table 2 in details. Then, obtained scores for all traits were summed and averaged for each landrace separately. The final rank for each landrace was determined considering the analysis of all traits. Therefore, based on this method drought-tolerant plants demonstrating lowest reduction in the traits during drought stress (highest relative value) will have the lowest score.

\subsubsection{Screening by the drought factor index (DFI)}

To calculate drought factor index (DFI) for assessment of drought stress tolerance in tomato plants, performance index $\left(\mathrm{PI}_{\mathrm{abs}}\right)$ of the landraces under control and stress conditions was considered. This method has been used by Boureima et al. (2012) to screen mutant germplasm of Sesamum (Sesame indicum), and by Cicek et al. (2019) to assess drought tolerance in sunflower hybrids. DFI was calculated based on the following equation:

$\mathrm{DFI}=\log A+2 \log B$

where $\mathrm{A}$ is the relative $\mathrm{PI}\left(\mathrm{PI}_{\text {stressed }} / \mathrm{PI}_{\text {non-stressed }}\right)$ measured at the third day of water withholding and $\mathrm{B}$ is the relative PI measured at the sixth day of drought stress exposure.
Table 2 How to score based on output of Duncan multiple range test (DMRT)

\begin{tabular}{llllllll}
\hline Letter & Score & Letter & Score & Letter & Score & Letter & Score \\
\hline $\mathbf{a}$ & 1 & $\mathbf{b}$ & 2 & $\mathbf{c}$ & 3 & $\mathbf{d}$ & 4 \\
$\mathbf{a b}$ & $1+[1-(1 / 2)]$ & $\mathbf{b c}$ & $2+[1-(1 / 2)]$ & $\mathbf{c d}$ & $3+[1-(1 / 2)]$ & $\mathbf{d e}$ & $4+[1-(1 / 2)]$ \\
$\mathbf{a b c}$ & $1+[1-(1 / 3)]$ & bcd & $2+[1-(1 / 3)]$ & $\mathbf{c d e}$ & $3+[1-(1 / 3)]$ & $\mathbf{d e f}$ & $4+[1-(1 / 3)]$ \\
abcd & $1+[1-(1 / 4)]$ & bcde & $2+[1-(1 / 4)]$ & $\mathbf{c d e f}$ & $3+[1-(1 / 4)]$ & $\mathbf{d e f g}$ & $4+[1-(1 / 4)]$ \\
abcde & $1+[1-(1 / 5)]$ & bcdef & $2+[1-(1 / 5)]$ & $\mathbf{c d e f g}$ & $3+[1-(1 / 5)]$ & & \\
abcdef & $1+[1-(1 / 6)]$ & bcdefg & $2+[1-(1 / 6)]$ & & & & \\
abcdefg & $1+[1-(1 / 7)]$ & & & & & & \\
\hline
\end{tabular}

The different letters assign different means of landraces. Namely, the landrace that have the highest relative value of a trait [(value of trait stressed $_{\text {value of trait }}$ non-stressed $\left.) \times 100\right]$, takes the letter $\mathbf{a}$ in DMRT and is scored 1 in screening with this method 
A factor of 2 is relative to accentuate the importance of a longer-term tolerance. Since in this study drought stress was imposed by water withholding, the relative PI in the 2 nd and 5th day after drought stress exposure was used for the assessment.

Boureima et al. (2012), working on drought stress in Sesame, showed that drought-tolerant plants should be able to tolerate drought stress for longer duration than drought sensitive genotypes, using DFI as the tolerance index. As a result, drought-tolerant plants showed the lowest reduction in the PI and have the highest DFI.

\subsection{Statistical analysis}

The experiment was conducted in a completely randomized design with four replicates. ANOVA results were considered significant at $p<0.05$ and mean comparison were done by Duncan multiple range test. Heat map of the cluster analysis was conducted using MetaboAnalyst and the cluster analysis calculated by the Euclidean distance between pairs of landraces, using Ward's method (Xia and Wishart, 2016). The heat map displays the plant response analytics by a warm-tocold color spectrum. Accordingly, the landraces with properresponse and weak-response respectively will be visible by warm and cold colors. Charts were graphed using OriginPro 8.5 software. Principal Component Analysis (PCA) was performed using MatLab 7.5 Toolbox.

\section{Results}

\subsection{Screening based on the DMRT method}

All measured traits of the tomatoes were affected following seven days exposure to water withholding condition. The analysis of variance for all traits indicates significant difference $(p<0.05)$ among seventeen landraces, two levels of drought stress (well watering and water withholding) and the interaction of landraces $\times$ drought (data not shown). As expected, the highest $\mathrm{DW}_{\text {Shoot }}, \mathrm{DW}_{\text {Root }}, \mathrm{FW}_{\text {Root }}, \mathrm{V}_{\text {Root }}$, number of leaves and the tallest plants were observed in control plants.

Supplementary Table $\mathrm{S} 1$ shows the scoring based on the DMRT method (explain in material and methods) and screening result based on all measured traits in this study. The minimum differences between the stressed and nonstressed plants (Score: 1) for height, number of leaves and $\mathrm{DW}_{\text {Shoot }}$ were attributed to Varamin, Shahroud and Semnan landraces, respectively (Supplementary Table S1). 8320 hybrid showed the minimum differences between stressed and non-stressed plants in case of $\mathrm{FW}_{\text {Root }}, \mathrm{DW}_{\text {Root }}$ and the $\mathrm{V}_{\text {Root }}$ (Supplementary Table $\mathrm{S} 1$ ). Number of leaves, $\mathrm{DW}_{\text {Root }}, \mathrm{V}_{\text {Root }}$ and $\mathrm{DW}_{\text {Shoot }}$ of Orumie landrace were extremely decreased by drought stress (highest score; Supplementary Table S1). This indicates that Orumie landrace is the most sensitive-drought landrace in terms of these parameters. Kurdesan, Rasht and Zanjan landraces showed the highest reduction in $\mathrm{FW}_{\text {Root }}$ under drought stress. In other words, maximum differences between the stressed and non-stressed plants in $\mathrm{FW}_{\text {Root }}$ were observed in Kurdesan, Rasht and Zanjan landraces (Supplementary Table S1).

The evaluate of plant responses to electrolyte leakage (EL) under drought condition showed that Varamin, Shahroud, Sirjan, Rasht and Zanjan landraces have taken score 1 for EL parameter (Supplementary Table S1), indicating these landraces showed the minimum differences between the stressed and non-stressed plants under drought stress conditions. Among all studied landraces, Neishabour landrace showed maximum differences between the stressed and control plants, taking highest score in DMRT screening (Supplementary Table S1).

The RWC which is the physiological consequence of cellular water deficit, were significantly different among landraces. As it already pointed out, 8320 hybrid and Zanjan landrace were tolerant to EL, but they did not show a proper respond to the RWC (Supplementary Table S1), meaning their RWC drastically changed by drought stress. Rasht landrace was the best landrace in the assessment of RWC and take score 1 in DMRT screening (Supplementary Table S). The value of RWC in non-stressed plants of Rasht was $84.70 \%$ and it reached to $62.94 \%$ in stressed plants. RWC value in drought-induced plants of Orumie $(32.98 \%)$ was very different from its control plants $(80.14 \%)$, so this landrace is considered as the most sensitive landrace when considering RWC (Supplementary Table S1).

Photosynthetic apparatus of all landraces and hybrids was damaged by drought stress exposure. The value of the parameters including: $\mathrm{F}_{\mathrm{M}} / \mathrm{F}_{0}, \mathrm{~F}_{\mathrm{V}} / \mathrm{F}_{\mathrm{M}}, \mathrm{PI}_{\mathrm{abs}}, \Phi \mathrm{E}_{0}$ and $\mathrm{ET}_{0} / \mathrm{RC}$ were decreased (Fig. 1a-e), while ABS/RC, TR $0 /$ RC, $\mathrm{DI}_{0} /$ $\mathrm{RC}$ and $\Phi \mathrm{D}_{0}$ were increased (Fig. 1f-i) in stress-exposed plants upon five days of water withholding. Some of the landraces maintained their photosynthetic performance in the same level of control plants and showed minimum percentage of changes compared to the control even five days after drought exposure (Fig. 1).

Except for Shahroud, Zanjan, Kurdestan and Varamin landraces, $\mathrm{F}_{\mathrm{M}} / \mathrm{F}_{0}$ of the tomato plants was adversely affected by drought stress. The highest change in $\mathrm{F}_{\mathrm{M}} / \mathrm{F}_{0}$ $(-74.15 \pm 0.55 \%)$ was detected in Bandar-Torkman landrace as a result of drought stress exposure (Fig. 1a). Results of screening by DMRT method for $\mathrm{F}_{\mathrm{M}} / \mathrm{F}_{0}$ parameter showed that Shahroud, Zanjan, Kurdestan and Varamin landraces well responded (Score 1) and Bandar-Torkman landrace weakly responded to drought stress condition (Score 5 in Supplementary Table S1). 


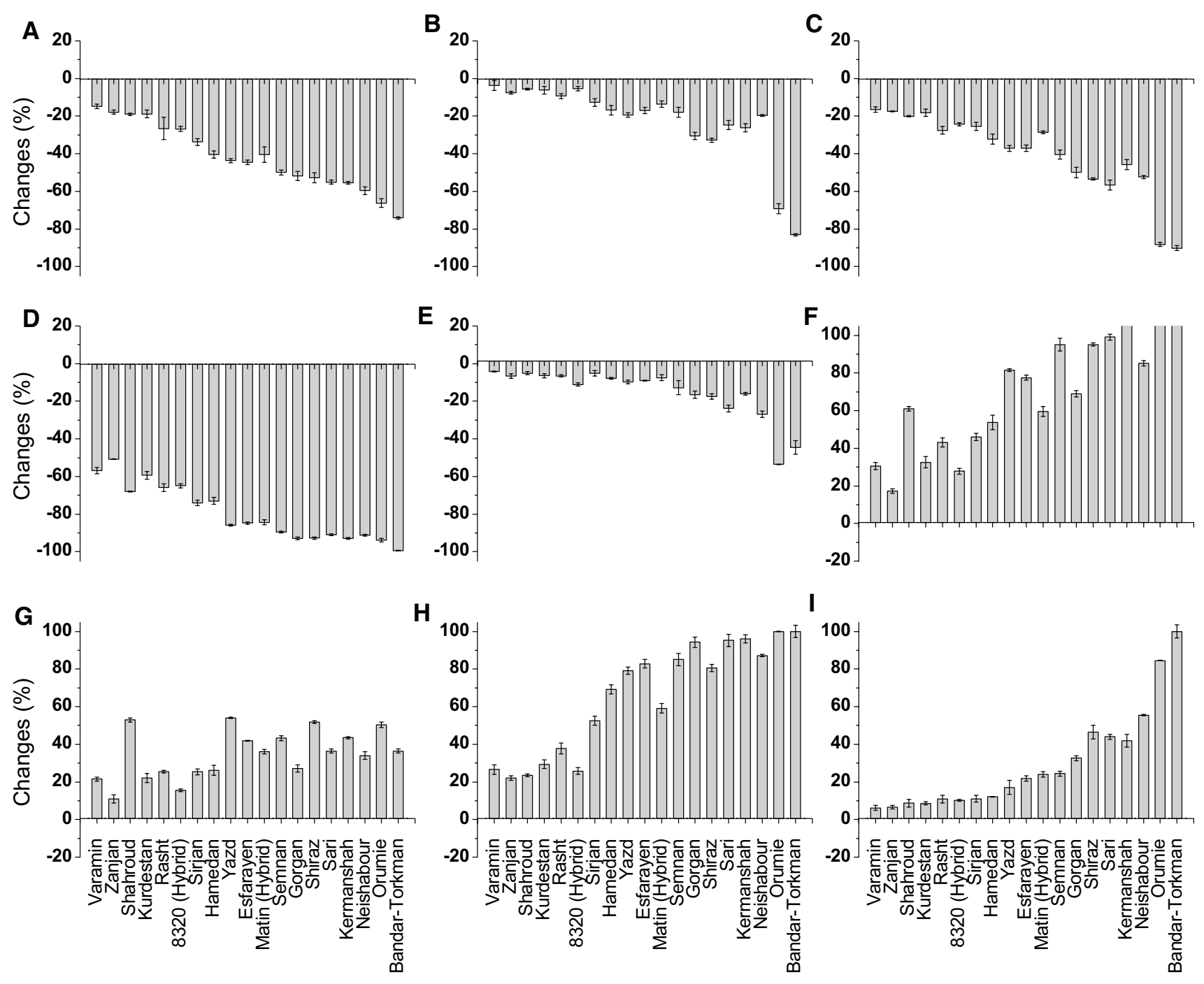

Fig. 1 Percentage of change in the value of the parameters related to the polyphasic Chl $a$ fluorescence (OJIP) kinetics including $\mathrm{F}_{\mathrm{M}} / \mathrm{F}_{0}$ (a), $\mathrm{F}_{\mathrm{V}} / \mathrm{F}_{\mathrm{M}}(\mathbf{b}), \Phi_{\mathrm{E} 0}(\mathbf{c}), \mathrm{PI}_{\mathrm{abs}}(\mathbf{d}), \mathrm{ET}_{0} / \mathrm{RC}(\mathbf{e}), \mathrm{ABS} / \mathrm{RC}(\mathbf{f}), \mathrm{TR}_{0} / \mathrm{RC}$ $(\mathbf{g}), \Phi_{\mathrm{D} 0}(\mathbf{h}), \mathrm{DI}_{0} / \mathrm{RC}$ (i) from leaves of 17 different tomato landraces and two hybrids under five days of water withholding compared to

The maximum quantum yield of PSII $\left(\mathrm{F}_{\mathrm{V}} / \mathrm{F}_{\mathrm{M}}\right)$, significantly decreased in stress-exposed of Bandar-Torkman plants compared to non-stressed plants $(-83.07 \pm 0.54 \%)$. This parameter exhibited minor changes in Varamin $(-3.67 \pm 2.75 \%), 8320$ hybrid $(-5.38 \pm 1.32 \%)$, Shahroud $(-5.61 \pm 0.48 \%)$, Kurdestan $(-6.16 \pm 2.08 \%)$ and Zanjan $(-7.56 \pm 0.79 \%)$ landraces in stress-exposed plants compared to control plants (Fig. 1b). Therefore, Bandar-Torkman taken the highest score and Varamin taken the minimum score in DMRT screening method (Supplementary Table S1).

$\Phi \mathrm{E}_{0}$ was considerably decreased in drought-induced plants in comparison with $\Phi \mathrm{E}_{0}$ of plants grown under control condition (Fig. 1c). The highest $\Phi \mathrm{E}_{0}$ under drought the well-watered plants. Bars represent mean \pm SD. Note: A droughttolerant plant has minimum change to control $(0 \%)$. Positive and negative symbols just indicate increase and decrease in the value of parameter in stressed plants compared to the control

condition (minimum change compared to control) was detected in Varamin landrace and the lowest (maximum change compared to control) was detected in Orumie and Bandar-Torkman landraces (Fig. 1c and Supplementary Table S1). Zanjan and kurdestan also responded well to drought and were screened as drought-tolerant plants in the case of $\Phi \mathrm{E}_{0}$ (Score 1.5; Supplementary Table S1).

$\mathrm{PI}_{\mathrm{abs}}$, one of the OIJP test parameters that provide valuable awareness about photosynthtic performance, considerably decreased under water withholding condition in all studied landraces (Fig. 1d). The lowest differences between stressed and non-stressed plants for $\mathrm{PI}_{\mathrm{abs}}$ parameter were observed in Zanjan landrace $(-50.80 \pm 0.1 \%)$ 
and the highest were detected in Bandar-Torkman landrace $(-99.4 \pm 0.09 \%)$.

Unlike $\mathrm{PI}_{\mathrm{abs}}, \mathrm{ET}_{0} / \mathrm{RC}$ did not show a significant reduction under drought stress. Maximum reduction of $\mathrm{ET}_{0} / \mathrm{RC}$ in drought-induced plants compared to control plants were observed in Orumie $(-53.59 \pm 3.69)$ and Bandar-Torkman $(-44.50 \pm 3.62)$ landraces and minimum were detected in Varamin landrace $(-4.16 \pm 0.17)$ (Fig. 1e). In addition to Varamin landrace, Shahroud, Sirjan, Kurdestan, Rasht and Zanjan landraces showed low changes in $\mathrm{ET}_{0} / \mathrm{RC}$ under water withholding condition (Fig. 1e).

The specific energy fluxes per RC for energy absorption (ABS/RC) significantly increased under drought stress (Fig. 1f). Variation range in this parameter was very large. $\mathrm{ABS} / \mathrm{RC}$ in drought-induced plants of BandarTorkman increased by six fold compared to the ABS/ $\mathrm{RC}$ of the control plants upon five days of water withholding $(601.96 \pm 3.33 \%)$ (Fig. 1f). In Zanjan landrace, ABS/RC was increased by only $17.27 \pm 1.2 \%$ (Fig. 1f). Apart from Bandar-Torkman landrace, ABS/RC value in stressed plants of Orumie and Kermanshah landraces were also drastically increased compared to control plants $(218.72 \pm 2.8 \%$ and $114.28 \pm 1.51 \%$ respectively $)$.

$\mathrm{TR}_{0} / \mathrm{RC}$ increased in stressed plants of Zanjan landrace by $11.02 \pm 2.17 \%$ and in Yazd landrace by $54.05 \pm 0.42 \%$ more than the control plants. Therefore, in DMRT screening method, Zanjan landrace has taken score 1 and Yazd has taken score 6 (Supplementary Table S1). The value of $\mathrm{TR}_{0} / \mathrm{RC}$ in stressed plants of Shahroud landrace was $52.92 \pm 1 \%$ more than the non-stressed plants; so in DMRT screening it taken a score similar to that of Yazd landrace (Supplementary Table S1).

$\Phi \mathrm{D}_{0}$, the quantum efficiency of energy dissipation, was dramatically increased in plants grown under stress condition (Fig. 1h). Shahroud, Kurdestan, Varamin and Zanjan landraces and 8320 hybrid with about $25 \%$ increase in $\Phi D_{0}$ of stressed plants were the top landraces in the assessment of $\Phi \mathrm{D}_{0}$ (Fig. 1h), taking score 1 in DMRT screening (Supplementary Table S1). Orumie and Bandar-Torkman showed most increase in $\Phi \mathrm{D}_{0}$ of stressed plants in comparison with the control plants (100\%; Fig. 1h) and were considered as the most sensitive landraces based on the DMRT screening (Supplementary Table S1).

Drought-stressed plants of Varamin and Zanjan landraces showed the lowest change in $\mathrm{DI}_{0} / \mathrm{RC}$ (Fig. 1i) and the minimum score of DMRT screening (Supplementary Table S1). 8320 hybrid, Kurdestan, Shahroud, Rasht, Hamedan and Sirjan landraces also showed the low increase in $\mathrm{DI}_{0} / \mathrm{RC}$ of plants grown under water withholding condition compared to the control plants (Fig. 1i). Orumie and Bandar-Torkman weakly responded to drought in the case of $\mathrm{DI}_{0} / \mathrm{RC}$ (Fig. 1i), similar to other studied parameters in the current study.
In general, results of DMRT screening for all studied parameters showed Varamin landrace is the most droughttolerant and Orumie landrace is the most drought-sensitive, amid of seventeen landraces and two hybrids in this study (Supplementary Table S1).

Figure 2 illustrates the visual response of Varamin, as a drought-tolerant plant, Esfarayen, as a moderately droughtsensitive plant, and Orumie, as a drought-sensitive plant in DMRT screening method on the fifth day of water withholding. Varamin landrace withstood better than the Esfarayen and Orumie landraces in response to five days water withholding.

For understanding landrace behavior under drought condition faster and more intuitive than getting rude information from the results, a heat map based on visual withstanding was drawn (Supplementary Fig. S2). Cluster analysis divided landraces into two main groups; the first group did not respond properly, which labeled as drought-sensitive whilst the second group divided into two subgroups (moderately drought-sensitive and drought-tolerant) (Supplementary Fig. S2). Esfarayen landrace can be indicated as an example of the moderately drought-sensitive subgroup and Varamin landrace can be considered as the droughttolerant subgroup (Supplementary Fig. S2-middle). Second subgroup illustrates proper response in terms of the JIP test parameters $\left(\mathrm{F}_{\mathrm{M}} / \mathrm{F}_{0}, \mathrm{~F}_{\mathrm{V}} / \mathrm{F}_{\mathrm{M}}, \Phi \mathrm{E}_{0}, \Phi \mathrm{D}_{0}, \mathrm{Pi}_{\mathrm{abs}}, \mathrm{ABS} / \mathrm{RC}, \mathrm{ET}_{0} /\right.$ $\mathrm{RC}, \mathrm{TR}_{0} / \mathrm{RC}$ and $\mathrm{DI}_{0} / \mathrm{RC}$ ) but for the growth parameters, RWC and EL respond either properly or weakly (Supplementary Fig. S2-left). In Varamin, Shahroud, Sirjan and Kurdestan landraces under drought condition, no considerable differences with the control condition was detected (Supplementary Table S1).

To elucidate the interrelationships within the studied landraces and traits, principal component analysis (PCA) was also carried out. This approach allows evaluating the stress effects on plants to recognize parameters that are most sensitive for plant stress responses. The results revealed that more than $80 \%$ of the total variance among the landraces was confirmed by the first four components of the PCA (Supplementary Table S2). The projections of values of parameters in the principle components (PCs), PCA1/PCA2/PC3/ $\mathrm{PC} 4$ present the influence of each parameter within total stress responses represented by the PCs. The first PC, corresponded to maximal variations of parameters, explained $39.62 \%$ of the total variation. PC1 was mainly explained by $\mathrm{F}_{\mathrm{M}} / \mathrm{F}_{0}, \mathrm{~F}_{\mathrm{V}} / \mathrm{F}_{\mathrm{M}}, \Phi \mathrm{E}_{0}, \Phi \mathrm{D}_{0}, \mathrm{Pi}_{\mathrm{abs}}, \mathrm{ABS} / \mathrm{RC}, \mathrm{ET}_{0} / \mathrm{RC}$ and $\mathrm{DI}_{0} /$ $\mathrm{RC}$ parameters, having most impact on the screening of landraces (Bolded in Supplementary Table S2). Other parameters did not contribute vigorously on this component. The second PC was described by height, number of leaf, $\mathrm{DW}_{\text {Root }}$ and $\mathrm{DW}_{\text {Soot }}$, placing in the next priority for the screening.

The stress induced variation in the studied landraces and two hybrids could be better represented in 2D (biplot) graph 
Fig. 2 Difference between the stressed and non-stressed plants for Varamin, as a droughttolerant plant, Esfarayen, as a moderately drought-sensitive plant, and Orumie, as a droughtsensitive plant on the fifth days of water withholding
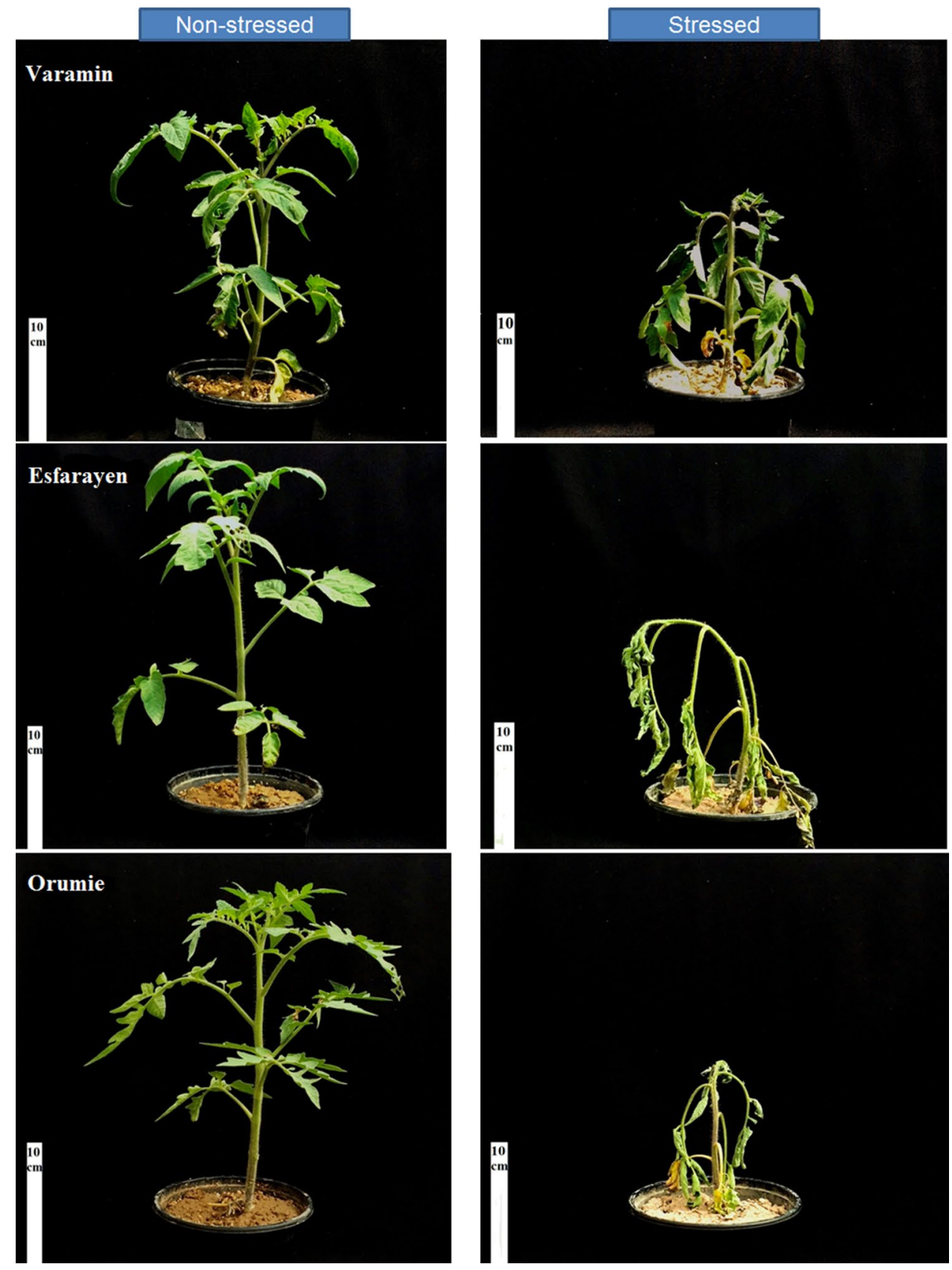

on a plane with PCA1 and PCA2 (Supplementary Fig. S3). The positions of points with coordinates PCA1/PCA 2 show the state of photosynthetic machinery and plant growth and represent the response of plants to stressors (Supplementary Fig. S3). The reduction of both values of PCA1 and PCA2 cause the deviations from the control plants. The vectors illustrate information of the relative contribution of each trait in the principal components formation that are visible by the direction and magnitude of the vectors.

Figure 3 (radar plot) represents the variations of draught stress response onto two different landraces caused by screening (one tolerant and one sensitive) based on eight most effective traits in the screening (obtained from PCA results in Supplementary Table S2). Results showed more variation in plant response to drought in Orumie landrace (drought-sensitive landrace) in comparison with Varamin landrace (drought-tolerant landrace) (Fig. 3a, b). For $\mathrm{F}_{\mathrm{V}} /$ $\mathrm{F}_{\mathrm{M}}$, Varamin landrace showed negligible difference from the control (Fig. 3a), but this difference in Orumie landrace was considerable (Fig. 3b). In both landraces, drought stress caused substantial changes in the $\mathrm{PI}_{\mathrm{abs}}$ value. $\mathrm{PI}_{\mathrm{abs}}$ is one of the most sensitive parameters for detection of photosynthetic performance under drought stress. 
Fig. 3 Radar plot for the parameters of OJIP-test affecting screening (derived from PCA, Table 1) from fluorescence transient exhibited by leaves of Varamin tomato landrace as a drought-tolerant landrace $\mathbf{a}$ and Orumie tomato landrace as a drought-sensitive landrace, $\mathbf{b}$ 5 days after water withholding. The values of the calculated parameters were shown as relative to those of the control plants (non-stressed)
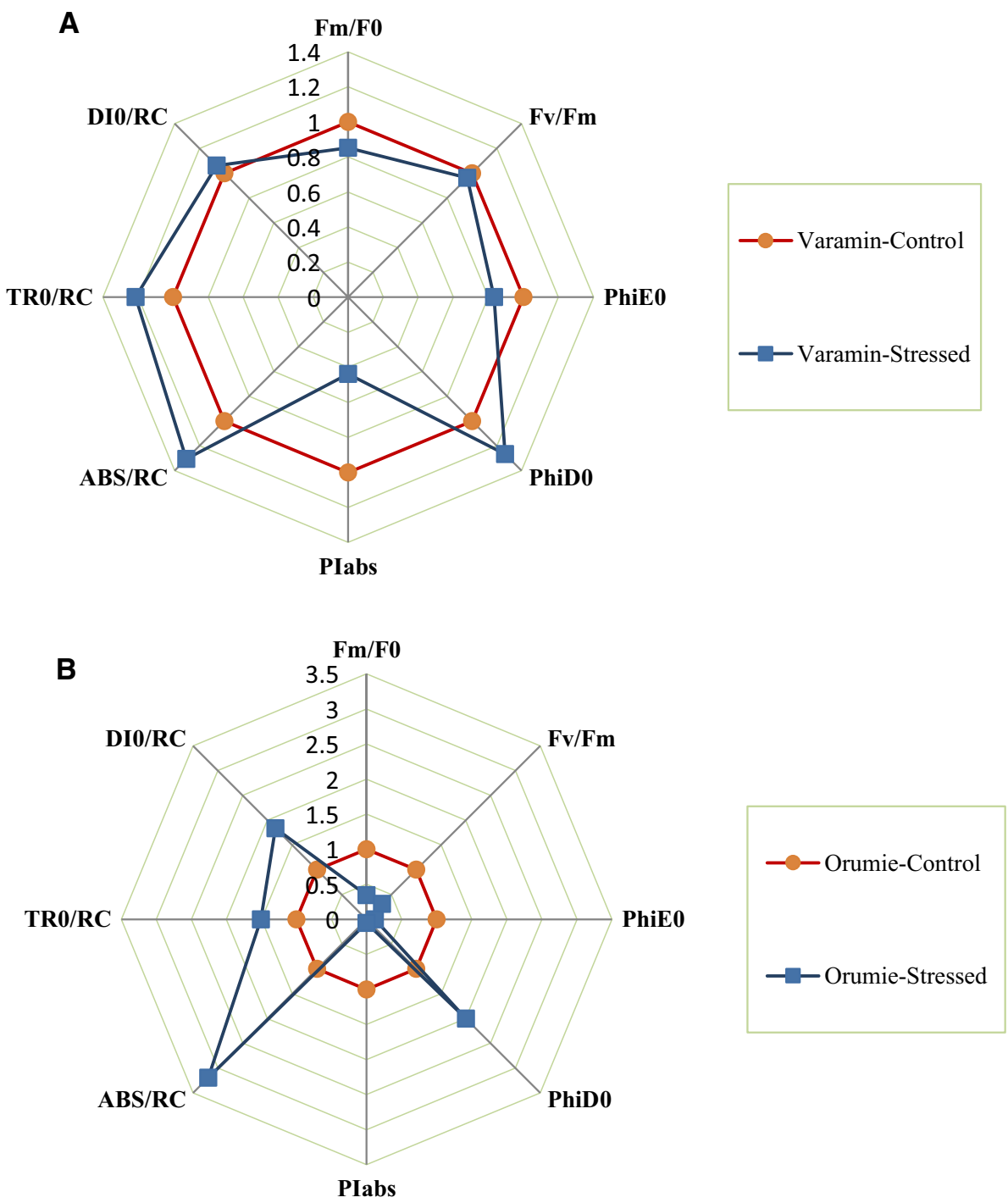

All the data of those eight parameters were normalized between -2 and 2 . The amount of the $\mathrm{F}_{\mathrm{M}} / \mathrm{F}_{0}, \mathrm{~F}_{\mathrm{V}} / \mathrm{F}_{\mathrm{M}}, \Phi_{\mathrm{E} 0}$ and $\mathrm{PI}_{\mathrm{abs}}$ parameters were categorized in three groups as high (e.g. 8320 Hybrid and Varamin), medium (e.g. Esfarayen and Semnan) and low (e.g. Orumie and Bandar-Torkman) in terms of tolerance to drought stress. Conversely, the value of $\Phi_{\mathrm{D} 0}, \mathrm{ABS} / \mathrm{RC}, \mathrm{TR}_{0} / \mathrm{RC}$ and $\mathrm{DI}_{0} / \mathrm{RC}$ parameters were low in drought-tolerant plant and high in drought-sensitive plant. As a consequence, high value for $\mathrm{F}_{\mathrm{M}} / \mathrm{F}_{\mathrm{M}}, \mathrm{F}_{\mathrm{V}} / \mathrm{F}_{\mathrm{M}}, \Phi_{\mathrm{E} 0}$ and $\mathrm{PI}_{\mathrm{abs}}$ parameters indicating more tolerance and high value for $\Phi_{\mathrm{D} 0}, \mathrm{ABS} / \mathrm{RC}, \mathrm{TR}_{0} / \mathrm{RC}$ and $\mathrm{DI}_{0} / \mathrm{RC}$ parameters shows less tolerance to drought.

\subsection{Screening by the drought factor index (DFI)}

The effect of drought stress on the performance index on the absorption basis $\left(\mathrm{PI}_{\mathrm{abs}}\right)$ in young fully expanded leaves during one week after water withholding is shown in Fig. 4.
Drought stress treatment had a significant negative effect on the PI of the most of the studied landraces. After two days, the leaves of stressed plants showed different reduction in relative $\mathrm{PI}_{\text {abs }}\left(\mathrm{PI}_{\text {stressed }} / \mathrm{PI}_{\text {non-stressed }}\right)$; for example 2\%, $23 \%$ and $30 \%$ reduction were detected in Zanjan, Semnan and Orumie landraces, respectively. Following five days of water withholding, the relative PI was dramatically decreased in all landraces except for Zanjan landrace, in which relative $\mathrm{PI}_{\mathrm{abs}}$ diminished just $21 \%$ in respect to the control (lowest negative impact) (Fig. 4), confirming a high stability of the photosynthetic performance in this landrace during drought stress.

In Supplementary Table S3, 17 different landraces and two hybrids were ordered from highest to lowest drought tolerance on the basis of their DFI values. Interestingly, the results of this screening method are in the same range as the former screening method (Supplementary Table S1). Zanjan landrace (drought tolerant landrace) showed the 
Fig. 4 Changes of performance index on the absorption basis $\left(\mathrm{PI}_{\mathrm{abs}}\right)$ in 17 different tomato landraces and two hybrids following 7 days of water withholding. Categorization of groups is adopted from the drought factor index (DFI) values in Table 2
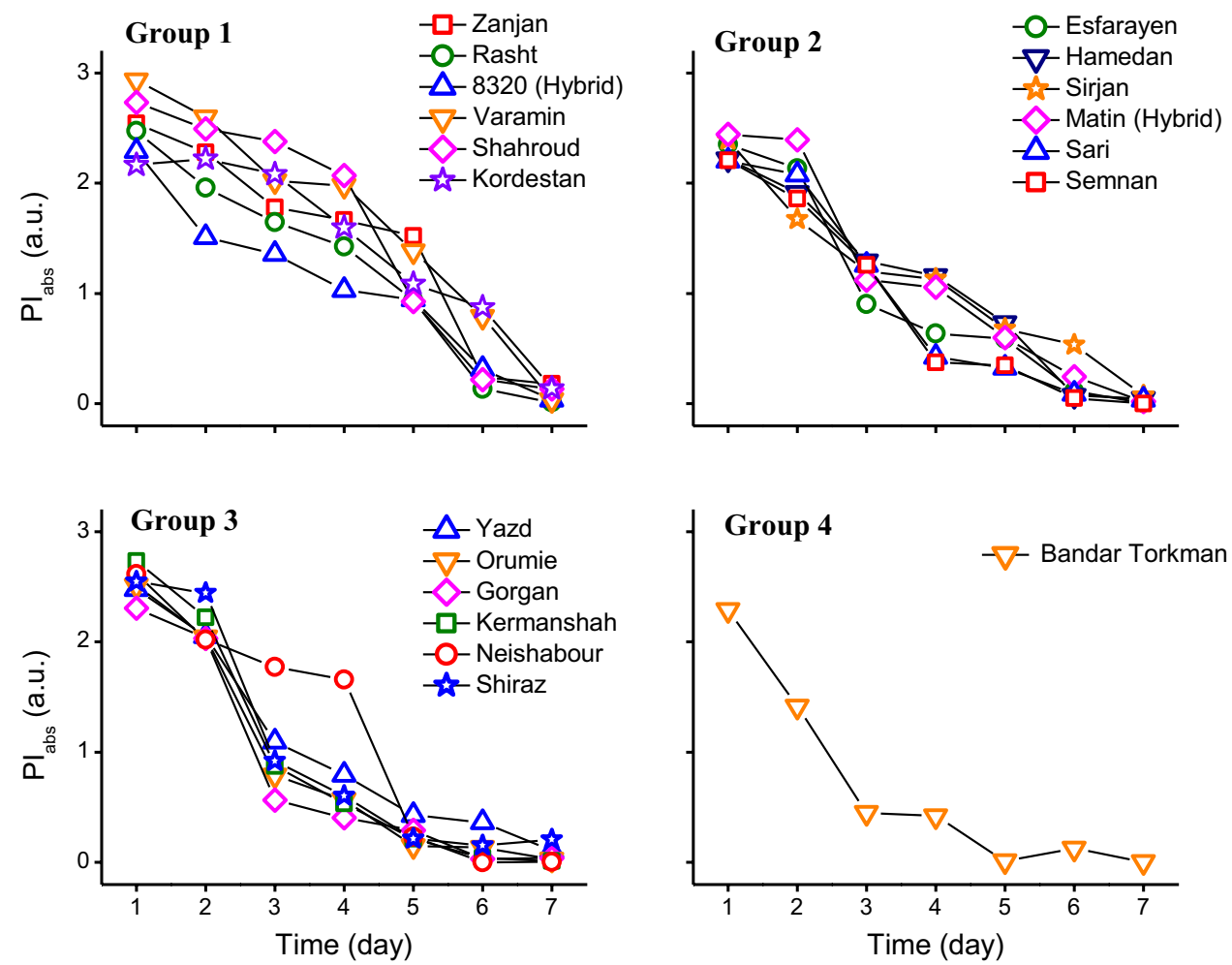

highest DFI $(-0.21)$ at the 5 th day of the water withholding. Rasht, Varamin, 8320 hybrid and Kurdestan had almost similar DFI (ranged between -0.76 and -0.95 ). The other landraces exhibited different DFI values and are shown in Supplementary Table S3. Bandar-Torkman had the smallest DFI (-4.82), which is indicative of highest sensitivity of this landraces to drought stress. The 17 landraces and two hybrids were arranged in four groups according to their DFI values (Supplementary Table S3). The first group consisted of Zanjan, Rasht, Varamin, Shahroud landraces and 8320 Hybrid with DFI values between -0.2 and -1.13 . Zanjan was considered as the most drought-tolerant and Rasht, Varamin, Shahroud and 8320 Hybrid as drought-tolerant plants. The second group had DFI values close to that of the first group $(-2.02<$ DFI $<-1.32)$, which considered as moderately drought-tolerant. The third group including Yazd, Gorgan, Kermanshah, Neishabour, Shiraz and Orumie had lower drought tolerance compared to the landraces in group II. The fourth group (Bandar-Torkman) had a lowest DFI value and considered as the most sensitive-landrace.

In general, the results of two methods of screening were almost similar with small differences. To indicate the differences between the results of the two screening methods, Sirjan and Kermanshah were belonged to the tolerant and moderately tolerant group based on the first method (DMRT method), whilst in the second method (DFI), they were in moderately tolerant and sensitive groups, respectively. The rest of the landraces showed almost the same results in both methods.

\section{Discussion}

In this experiment, we screened drought tolerant of 17 widely distributed landraces and two hybrids of tomato at the vegetative stage. Using two screening methods based on the Duncan's multiple range test (DMRT; First method of screening) and via drought factor index (DFI; second method of screening), landraces were arranged in three separated groups according to their tolerance to drought stress. Drought-tolerant group was consisted of Varamin, 8320 (Hybrid), Shahroud, Sirjan, Kurdestan, Rasht and Zanjan; which can be suggested as preferable and superior landraces for cultivation in areas with shortage of water. Moderately drought-sensitive group was consisted of Matin (Hybrid), Hamedan, Esfarayen, Semnan, Sari and Kermnshah, and Drought-sensitive group was consisted of Gorgan, Yazd, Neishabur, Shiraz, Bandar-Torkman and Orumie. This screening provided a number of useful information for the assessment of the drought tolerance in a collection of $S$. lycopersicum $\mathrm{L}$ landraces.

Growth parameters, fast $\mathrm{Chl}$ fluorescence induction curves (OJIP), electrolyte leakage and relative water content (RWC) were the main parameters used for the screening of landraces. Rosales-Serna et al. (2000) suggested that drought 
stress is a complicated stressor and different aspects of plant growth and physiology should be taken into account for evaluation of a population in response to drought stress. Therefore, in the present study screening for drought tolerance was complemented considering both growth and physiological analyses. To do so, different traits including biophysical analysis of Chl fluorescence, leaf water status as function of relative water content (RWC), electrolyte leakage, reflects damage to cell membrane, and growth measurements were considered for evaluation of the effects of drought on plants and for screening the landraces.

As it is expected, growth parameters of stressed plants including height, leaf number, $\mathrm{DW}_{\text {Shoot }}, \mathrm{V}_{\text {Root }}, \mathrm{FW}_{\text {Root }}$, $\mathrm{DW}_{\text {Root }}$ were reduced by 7 days of exposure to water withholding conditions.

Electrolyte leakage was highly increased in drought stressed plants. Results of previous researches showed that electrolyte leakage is mainly related to $\mathrm{K}^{+}$efflux from the plant cells, which is interceded by cation conductance of plasma membrane (Demidchik et al. 2013). In moderate drought stress condition, $\mathrm{K}^{+}$efflux could stimulate catabolic processes and save energy for adaptation and repair processes by playing an essential role as a 'metabolic switch' in anabolic reactions (Demidchik et al. 2010). However, under severe drought stress conditions, reactive oxygen species (ROS) dramatically accumulate; lead to programmed cell death (PCD) and leakage of cellular electrolytes (Apel and Hirt 2004).

Our results also illustrated that drought stress negatively influenced the leaf water status as exhibited by reduction in RWC. Drought-tolerant landraces, (e.g. Rasht) had higher RWC, which is indicative of ability to absorb water from the soil and to conserve water inside the leaf under drought stress. RWC under drought conditions can be a reflectance of the function of gas exchange processes in plant such as stomatal behavior (Rezaei Nejad and van Meeteren 2008), stomatal conductance $\left(\mathrm{g}_{\mathrm{s}}\right)$ (Bauerle et al. 2004), transpiration rate and photosynthesis (Outlaw and De Vlieghere-He 2001). Drought stress first reduces $g_{s}$, then RWC and photosynthesis begin to decrease. A sharp decrease in $g_{s}$ with change in the RWC indicates that the signals sent from the root in response to desiccation, are likely to cause stomatal closure and to reduce photosynthesis (Aliniaeifard and van Meeteren 2013). Aliniaeifard and van Meeteren (2014) proposed that reducing the RWC reduces the conductivity of the stomata and thus the entry of carbon dioxide $\left(\mathrm{CO}_{2}\right)$ into the leaf will be diminished which reduces photosynthesis. A good regulation of the stomata aperture is needed to permit sufficient $\mathrm{CO}_{2}$ uptake for photosynthesis, while inhibiting excessive water loss through transpiration under drought stress condition (Pantin et al. 2013). In general, closing of stomata and decrease in leaf RWC is the first effect of drought stress, which in long term interferes with the production of photosynthetic materials and reduces plant growth.

OJIP test is shown to be a proxy to detect PSII bioenergetics and indicates changes in the status and function of PSII reaction centers, antenna, as well as in donor and acceptor sides of PSII. In our investigation, we showed that the ETC is appropriately operated in plants grown under control condition. However, when plants exposed to water withholding condition, decrease in the $\mathrm{F}_{\mathrm{M}} / \mathrm{F}_{0}$, relative maximal variable fluorescence, $\mathrm{F}_{\mathrm{V}} / \mathrm{F}_{\mathrm{M}}$, maximum quantum yield of primary PSII photochemistry, $\Phi \mathrm{E}_{0}$, quantum yield of electron transport, $\mathrm{ET}_{0} / \mathrm{RC}$, electron transport flux per reaction center, and $\mathrm{PI}_{\mathrm{abs}}$, performance index on the absorption basis, and increase in $\Phi \mathrm{D}_{0}$, the quantum efficiency of energy dissipation, ABS/RC, energy absorption per reaction center, $\mathrm{TR}_{0} /$ $\mathrm{RC}$, trapped energy flux per reaction center, and $\mathrm{DI}_{0} / \mathrm{RC}$, dissipated energy flux per reaction center, occurred when compared to their values under control conditions (Fig. 1). Indeed, these events occur to develop a photosynthesis apparatus with lower vulnerability (Schaeffer et al. 2012). In general, Varamin landrace, as a tolerant landraces, is capable of sustaining the photosynthetic electron transport machinery under drought condition in comparison with the Orumie landrace, as a sensitive ones (Kalaji et al. 2016; Franić et al. 2017).

It has been reported that different abiotic stress conditions such as salinity (Mathur et al. 2013), nutrient deficiency (Kalaji et al. 2014), heat (Jedmowski and Brüggemann 2015; Zhou et al. 2015), light (Bayat et al. 2018; Aliniaeifard et al. 2018), low pH (Long et al. 2017), drought (Guha et al. 2013; Cicek et al. 2019) and chilling (Dong et al. 2020) negatively influenced the photosynthetic performance in different plant species.

$\mathrm{F}_{\mathrm{M}} / \mathrm{F}_{0}$ decreased as a result of water withholding stress. This decrease can be related to damage the RCs and to increase in the number of inactive RCs leading to increase in the fluorescence as well as reduce the excitation energy transfer from antenna complex towards RCs (Kalaji et al. 2016; Aliniaeifard et al. 2018). During an ideal condition without any additional stress, the total PSII pool can be completely inactivate and retrieve without a detectable photoinhibition (Aliniaeifard et al. 2018). In case the plants also bears other stresses like water deficiency a drastic population of inactivated PSII RCs may aggregate inside the thylakoid stacks, causing dissipation of light energy under photoinhibition conditions (Bayat et al. 2018). Damage to thylakoid membranes and deactivation of PSII reaction centers restrict the upstream energy transfer of PSII (Rapacz et al. 2015). Rapacz et al. (2011) suggested that there is a positive relationship between the degree of thylakoid membrane damage and the trustworthiness of the Chl fluorescence data in estimate of freezing tolerance. The specific energy flux per $\mathrm{RC}$ on absorption basis (ABS/RC) showed an increase in 
sensitive tomato landraces whereas for tolerant landraces remained almost at the same level as detected in the control. According to Jedmowski and Brüggemann, (2015) inactivation of some RCs as already mentioned, increases the ABS/ $\mathrm{RC}$ under drought stress. Another reasons for increase in $\mathrm{ABS} / \mathrm{RC}$ are degradation of $\mathrm{Chl}$ through an early leaf senescence induced by drought stress (Boureima et al. 2012); regrouping of antenna from inactive PSII RCs to active (Kalaji et al., 2016). Hence, the dramatic increase in ABS/ $\mathrm{RC}$ in sensitive landraces can be attributed to decrease in effective antenna size as well as PSII inactivation (Çiçek et al. 2019). When electron transport per $\mathrm{RC}\left(\mathrm{ET}_{0} / \mathrm{RC}\right)$ is declined, increase in the rate of energy dissipation $\left(\mathrm{DI}_{0} /\right.$ $\mathrm{RC})$ of un-trapped excitations $\left(\mathrm{TR}_{0} / \mathrm{RC}\right)$ occurs as a result of drought exposure (Guha et al. 2013; Hosseini et al. 2019). This absence of a positive correlation between $\mathrm{ET}_{0} /$ $\mathrm{RC}$ and $\mathrm{DI}_{0} / \mathrm{RC}$ and $\mathrm{TR}_{0} / \mathrm{RC}$ may be the result of the stress induced damage of PSII RCs, which may increase energy flows observed in single active RC (Rapacz et al. 2015). Reduction of $\mathrm{ET}_{0} / \mathrm{RC}$ might prevent reduction of the ETC, which facilitate dissipation of excessive energy to minimize photo-oxidative damage in the thylakoid membrane (Guha et al. 2013).

Although in some studies, $\mathrm{F}_{\mathrm{V}} / \mathrm{F}_{\mathrm{M}}$ or $\Phi \mathrm{P}_{0}$, the maximum quantum yield of primary photochemistry, were not reported as the best parameter for estimation of freezing tolerance of triticale and wheat (Taulavuori et al. 2000; Rapacz et al. 2011), while in other studies it has been demonstrated that $\mathrm{F}_{\mathrm{V}} / \mathrm{F}_{\mathrm{M}}$ is an effective tool for early identification of heat tolerant tomato genotypes (Zhou et al. 2015). In the present study, $\mathrm{F}_{\mathrm{V}} / \mathrm{F}_{\mathrm{M}}$ contributed in the total variation of principal components (PCs) on 17 tomato landraces and two hybrids (Supplementary Table S2) and considered as a good indicator for estimation of drought tolerance. Like previous reports (Franić et al. 2017; Çiçek et al. 2019), our data showed that the ratio of $\mathrm{F}_{\mathrm{V}} / \mathrm{F}_{\mathrm{M}}$ decreased in drought-exposed plants. The ratio of $\mathrm{F}_{\mathrm{V}} / \mathrm{F}_{\mathrm{M}}$ is not only influenced by the intensity of $\mathrm{F}_{0}$, as the initial intensity of Chl fluorescence, or $\mathrm{F}_{\mathrm{M}}$, maximum value of fluorescence under saturating illumination, but the relative value between these two parameter is the main determinant (Guha et al. 2013). Reduction in the $F_{V} / F_{M}$ under stress conditions may be due to reduction in the leaf pigment content, total phenolic content and swollen chloroplasts with decomposed starch grain in stress-sensitive plants than the tolerant ones (Zhang et al. 2014; Sharma et al. 2015; Zhou et al. 2015). In this regard, the basic role of stomatal regulation should not be overlooked. As explained above, drought stress reduces photosynthesis due to its effect on closing the stomatal aperture and thus reducing $\mathrm{CO}_{2}$ access in the mesophyll (instead of directly affecting the rate of apparent photosynthesis) (Aliniaeifard and Van Meeteren 2014). It has been reported many times in previous studies that the closure of the stomata to prevent water loss is one of the primary responses to drought stress (Holbrook et al. 2002; Buckley 2005). Reduction in both photosynthesis and the conduction of stomata will be occurring under drought stress (Aliniaeifard et al. 2014). Drought-tolerant plants have some mechanisms to control the stomatal movements that in addition to preventing water loss can increase $g_{s}$ in low water conditions. For example they can deal with lack of water by raising the level of hormones like ABA that can control the guard cells to close or open the stomata to avoid losing water or dying of starvation. This management led to rise in internal $\mathrm{CO}_{2}$ concentration in leaves, preserve the net photosynthesis rate $\left(\mathrm{P}_{\mathrm{N}}\right)$ and subsequently increase the $\mathrm{F}_{\mathrm{V}} / \mathrm{F}_{\mathrm{M}}$ and $\mathrm{PI}_{\text {abs }}$ (Rapacz et al. 2015).

Based on PCA analysis, $\mathrm{PI}_{\mathrm{abs}}$ was one of the sensitive parameters to drought stress (Supplementary Table S2). Therefore, in the present study, drought factor index (DFI) based on the $\mathrm{PI}_{\mathrm{abs}}$ was used for ranking of 17 landraces as well as two hybrids in response to water withholding condition (Supplementary Table S3). This parameter has been used to forejudge the response of different plant species to diverse range of stresses. For example, Boureima et al. (2012) ranked 21 drought-induced mutant lines by DFI based on relative $\mathrm{PI}_{\text {abs }}$ (stressed/control). Such screening was also confirmed by other authors (Chaerle et al. 2007; Jedmowski and Brüggemann 2015; Dong et al. 2020). Our data also showed that in cases when leaves are heavily damaged one week after water withholding, it is late to use $\mathrm{PI}_{\mathrm{abs}}$ for testing the drought tolerance (Fig. 4). Decrease of this important parameter under stress conditions showing dampening of electron transport capacity. In agreement with these findings, Boureima et al, (2012) suggested a liner correlation between the relative driving force for photosynthesis of sesame cultivars (Sesamum indicum) and the relative electron transport capacity. Same relationship was also showed on different plant species exposed to drought stress (Strauss et al. 2006; Oukarroum et al. 2007). Therefore, the reduction of plant vitality in drought-sensitive landraces can also be related to the loss of electron transport capacity.

\section{Conclusions}

Currently, many research teams all around the world are focusing on issues related to the impacts of drought stress on crop yields and food security. Introducing new source of drought tolerance for tomato plants can help to increase yield and quality of this important crop. Using an approach for fast screening is of great significance for further expansion of the cultivation area of this crop. In the present study we used two methods of screening to detect the drought tolerance level of 17 tomato landraces and two hybrids. First method was based on output of Duncan's multiple range test (DMRT) for all the studied parameters 
and second was a drought factor index (DFI) based on performance index on the absorption basis $\left(\mathrm{PI}_{\mathrm{abs}}\right)$. According to our results, DMRT method is quite applicable and easy to use in screening studies. Therefore, we recommend that researchers use this method when they want to screen a large number of plants in terms of numerous parameters. Our screening results clearly categorized the landraces into three groups: drought-tolerant, moderately droughtsensitive and drought-sensitive. As a breakthrough in this study, we found Varamin landrace as a most drought-tolerant landrace even more than the commercial hybrids. This landrace exhibited closer values to control levels under water withholding condition. Tomato landraces were properly categorized in three groups (tolerant, moderately sensitive and sensitive) based on both DMRT and DFI screening methods. We found that adapted landraces to dry climates had a higher tolerance to drought stress. Principal component analysis (PCA) demonstrated that $\mathrm{F}_{\mathrm{M}} / \mathrm{F}_{0}, \mathrm{~F}_{\mathrm{V}} /$ $\mathrm{F}_{\mathrm{M}}, \Phi \mathrm{E}_{0}, \Phi \mathrm{D}_{0}, \mathrm{PI}_{\mathrm{abs}}, \mathrm{ABS} / \mathrm{RC}, \mathrm{ET}_{0} / \mathrm{RC}$ and $\mathrm{DI}_{0} / \mathrm{RC}$ are the most sensitive parameters for detection of impact of drought stress on tomato plants.

Supplementary Information The online version contains supplementary material available at https://doi.org/10.1007/s13580-020-00328-5.

Acknowledgements The authors thanked the Gorgan University of Agricultural Sciences and Natural Resource, Iran for providing research facilities and fund. The study would not have been possible without the generous and willing cooperation of staff and people of Abureihan Campus, University of Tehran, Iran.

Author contributions KM and SA conceived the study; NS carried out the experiments and wrote the manuscript; NS, SA and SJM analyzed the data. SA, SJM, VA and JMA read and approved the final version of the manuscript.

\section{Compliance with ethical standards}

Conflict of interest The authors are affirming that the present study represents original work that is not being considered for publication in another journal with a substantial circulation. This study has been reviewed and approved by all the authors and there are no conflicts to declare.

Open Access This article is licensed under a Creative Commons Attribution 4.0 International License, which permits use, sharing, adaptation, distribution and reproduction in any medium or format, as long as you give appropriate credit to the original author(s) and the source, provide a link to the Creative Commons licence, and indicate if changes were made. The images or other third party material in this article are included in the article's Creative Commons licence, unless indicated otherwise in a credit line to the material. If material is not included in the article's Creative Commons licence and your intended use is not permitted by statutory regulation or exceeds the permitted use, you will need to obtain permission directly from the copyright holder. To view a copy of this licence, visit http://creativecommons.org/licenses/by/4.0/.

\section{References}

Adhikari KN, Buirchell BJ, Thomas GJ, Sweetingham MW, Yang H (2009) Identification of anthracnose resistance in Lupinus albus L. and its transfer from landraces to modern cultivars. Crop Pasture Sci 60:472-479. https://doi.org/10.1071/CP08092

Aliniaeifard S, Van Meeteren U (2014) Natural variation in stomatal response to closing stimuli among Arabidopsis thaliana accessions after exposure to low VPD as a tool to recognize the mechanism of disturbed stomatal functioning. J Exp Bot 65:6529-6542. https://doi.org/10.1093/jxb/eru370

Aliniaeifard S, Van Meeteren U (2016a) Stomatal characteristics and desiccation response of leaves of cut chrysanthemum (Chrysanthemum morifolium) flowers grown at high air humidity. Sci Hortic 205:84-89. https://doi.org/10.1016/j.scienta.2016.04.025

Aliniaeifard S, Van Meeteren U (2016b) Natural genetic variation in stomatal response can help to increase acclimation of plants to dried environments. In: International symposium on the role of plant genetic resources in reclaiming lands and environment deteriorated by human and 1190, pp 71-76. https://doi.org/10.17660 /ActaHortic.2018.1190.12

Aliniaeifard S, Hajilou J, Tabatabaei SJ (2016) Photosynthetic and growth responses of olive to proline and salicylic acid under salinity condition. Not Bot Horti Agrobot Cluj Napoca 44:579-585. https://doi.org/10.15835/nbha44210413

Aliniaeifard S, Malcolm Matamoros P, Van Meeteren U (2014) Stomatal malfunctioning under low Vapor Pressure Deficit (VPD) conditions: Induced by alterations in stomatal morphology and leaf anatomy or in the ABA signaling? Physiol Plant 152:688-699. https://doi.org/10.1111/ppl.12216

Aliniaeifard S, Seif M, Arab M, Zare Mehrjerdi M, Li T, Lastochkina $\mathrm{O}$ (2018) Growth and photosynthetic performance of Calendula officinalis under monochromatic red light. Int J Hortic Sci 5:123132. https://doi.org/10.22059/ijhst.2018.261042.248

Apel K, Hirt H (2004) Reactive oxygen species: metabolism, oxidative stress, and signal transduction. Annu Rev Plant Biol 55:373-399. https://doi.org/10.1146/annurev.arplant.55.031903.141701

Bauerle WL, Whitlow TH, Setter TL, Vermeylen FM (2004) Abscisic acid synthesis in Acer rubrum L. leaves-a vapor-pressure-deficitmediated response. J Am Soc Hortic Sci 129:182-187. https://doi. org/10.21273/JASHS.129.2.0182

Bayat L, Arab M, Aliniaeifard S, Seif M, Lastochkina O, Li T (2018) Effects of growth under different light spectra on the subsequent high light tolerance in rose plants. AoB Plants 10:052. https://doi. org/10.1093/aobpla/ply052

Boureima S, Oukarroum A, Diouf M, Cisse N, Van Damme P (2012) Screening for drought tolerance in mutant germplasm of sesame (Sesamum indicum) probing by chlorophyll a fluorescence. Environ Exp Bot 81:37-43. https://doi.org/10.1016/j.envex pbot.2012.02.015

Buckley TN (2005) The control of stomata by water balance. New Phytol 168:275-292. https://doi.org/10.1111/j.1469-8137.2005.01543 .X

Cabello R, De Mendiburu F, Bonierbale M, Monneveux P, Roca W, Chujoy E (2012) Large-scale evaluation of potato improved varieties, genetic stocks and landraces for drought tolerance. Am J Potato Res 89:400-410. https://doi.org/10.1007/s 1223 0-012-9260-5

Cabello R, Monneveux P, De Mendiburu F, Bonierbale M (2013) Comparison of yield based drought tolerance indices in improved varieties, genetic stocks and landraces of potato (Solanum tuberosum L.). Euphytica 193:147-156. https://doi.org/10.1007/s1068 1-013-0887-1

Chaerle L, Leinonen I, Jones HG, Van Der Straeten D (2007) Monitoring and screening plant populations with combined thermal 
and chlorophyll fluorescence imaging. J Exp Bot 58:773-784. https://doi.org/10.1093/jxb/erl257

Çiçek N, Pekcan V, Arslan Ö, Erdal ŞÇ, Nalçaiyi ASB, Çil AN, Şahin V, Kaya Y, Ekmekçi Y (2019) Assessing drought tolerance in field-grown sunflower hybrids by chlorophyll fluorescence kinetics. Braz J Bot 42:249-260. https://doi.org/10.1007/ s40415-019-00534-1

De Almeida Cançado GM (2011) The importance of genetic diversity to manage abiotic stress. Abiotic stress in plants-Mechanisms and adaptations, p 351. https://doi.org/10.5772/22397

Demidchik V, Cuin TA, Svistunenko D, Smith SJ, Miller AJ, Shabala S, Sokolik A, Yurin V (2010) Arabidopsis root K+-efflux conductance activated by hydroxyl radicals: single-channel properties, genetic basis and involvement in stress-induced cell death. J Cell Sci 123:1468-1479. https://doi.org/10.1242/jcs.064352

Dong Z, Men Y, Liu Z, Li J, Ji J (2020) Application of chlorophyll fluorescence imaging technique in analysis and detection of chilling injury of tomato seedlings. Comput Electron Agric 168:105109. https://doi.org/10.1016/j.compag.2019.105109

Farooq M, Wahid A, Kobayashi N, Fujita D, Basra SMA (2009) Plant drought stress: effects, mechanisms and management. In: Lichtfouse E, Navarrete M, Debaeke P, Véronique S, Alberola C (eds) Sustainable agriculture. Springer, Dordrecht. https://doi. org/10.1007/978-90-481-2666-8_12

Franić M, Galić V, Ledenčan T, Jambrović A, Brkić I, Zdunić Z, Brkić A, Brkić J, Šimić D (2017) Changes of chlorophyll a fluorescence parameters in water limited maize IBM population. In 52. hrvatski i 12. međunarodni simpozij agronoma

Galkovskyi T, Mileyko Y, Bucksch A, Moore B, Symonova O, Price CA, Topp CN, Iyer-Pascuzzi AS, Zurek PR, Fang S, Harer J (2012) GiA Roots: software for the high throughput analysis of plant root system architecture. BMC Plant Biol 12:116. https:// doi.org/10.1186/1471-2229-12-116

Gindaba J, Rozanov A, Negash L (2004) Response of seedlings of two Eucalyptus and three deciduous tree species from Ethiopia to severe water stress. For Ecol Manag 201:119-129. https:// doi.org/10.1016/j.foreco.2004.07.009

Guha A, Sengupta D, Reddy AR (2013) Polyphasic chlorophyll a fluorescence kinetics and leaf protein analyses to track dynamics of photosynthetic performance in mulberry during progressive drought. J. Photochem. Photobiol B Biol 119:71-83. https://doi. org/10.1016/j.jphotobiol.2012.12.006

Gupta C, Salgotra RK, Mahajan G (2020) Future threats and opportunities facing crop wild relatives and landrace diversity. In Rediscovery of genetic and genomic resources for future food security. Springer, Singapore, pp 351-364. https://doi. org/10.1007/978-981-15-0156-2_14

Hassannejad S, Ghafarbi SP, Lotfi R (2020) The effect of nicosulfuron and bentazon on photosynthetic performance of common cocklebur (Xanthium strumarium L.). Environmental and Sustainability Indicators, p 100026. https://doi.org/10.1016/j.indic .2020 .100026

Henareh M, Dursun A, Mandoulakani BA (2015) Genetic diversity in tomato landraces collected from Turkey and Iran revealed by morphological characters. Acta Sci Pol Hortorum Cultus 14:87-96

Holbrook NM, Shashidhar VR, James RA, Munns R (2002) Stomatal control in tomato with ABA-deficient roots: response of grafted plants to soil drying. J Exp Bot 53:1503-1514. https://doi. org/10.1093/jexbot/53.373.1503

Hosseini A, Mehrjerdi MZ, Aliniaeifard S, Seif M (2019) Photosynthetic and growth responses of green and purple basil plants under different spectral compositions. Physiol Mol Biol Plants 25:741752. https://doi.org/10.1007/s12298-019-00647-7

Jedmowski C, Brüggemann W (2015) Imaging of fast chlorophyll fluorescence induction curve (OJIP) parameters, applied in a screening study with wild barley (Hordeum spontaneum) genotypes under heat stress. J Photoch Photobio B 151:153-160. https:// doi.org/10.1016/j.jphotobiol.2015.07.020

Jiang X, Zhao Y, Tong L, Wang R, Zhao S (2019) Quantitative analysis of tomato yield and comprehensive fruit quality in response to deficit irrigation at different growth stages. HortScience 54:14091417. https://doi.org/10.21273/HORTSCI14180-19

Kafi FM, Nezami A, Hosseini H, Masoumi A (2005) Physiological effects of drought stress by polyethylene glycol on germination of lentil (Lens culinaris Medik.) genotypes. Iran J Field Crops Res 3:69-80 ((in Persian))

Kalaji HM, Jajoo A, Oukarroum A, Brestic M, Zivcak M, Samborska IA, Cetner MD, Łukasik I, Goltsev V, Ladle RJ (2016) Chlorophyll a fluorescence as a tool to monitor physiological status of plants under abiotic stress conditions. Acta Physiol Plant 38:102. https://doi.org/10.1007/s11738-016-2113-y

Kalaji HM, Oukarroum A, Alexandrov V, Kouzmanova M, Brestic M, Zivcak M, Samborska IA, Cetner MD, Allakhverdiev SI, Goltsev V (2014) Identification of nutrient deficiency in maize and tomato plants by in vivo chlorophyll a fluorescence measurements. Plant Physiol Biochem 81:16-25. https://doi.org/10.1016/j.plaph y.2014.03.029

Kalhor MS, Aliniaeifard S, Seif M, Asayesh EJ, Bernard F, Hassani B, Li T (2018) Enhanced salt tolerance and photosynthetic performance: implication of $\gamma$-amino butyric acid application in saltexposed lettuce (Lactuca sativa L.) plants. Plant Physiol Biochem 130:157-172. https://doi.org/10.1016/j.plaphy.2018.07.003

Khan MIR, Singh A, Poór P (2020) Improving abiotic stress tolerance in plants. Taylor \& Francis Group, New York

Küpper H, Benedikty Z, Morina F, Andresen E, Mishra A, Trtilek M (2019) Analysis of OJIP chlorophyll fluorescence kinetics and QA reoxidation kinetics by direct fast imaging. Plant Physiol 179:369-381. https://doi.org/10.1104/pp.18.00953

Lastochkina O, Aliniaeifard S, Seifikalhor M, Yuldashev R, Pusenkova L, Garipova S (2019) Plant growth-promoting bacteria: biotic strategy to cope with abiotic stresses in wheat. In Wheat production in changing environments. Springer, Singapore, pp 579-614. https://doi.org/10.1007/978-981-13-6883-7_23

Lázaro A (2018) Tomato landraces: an analysis of diversity and preferences. Plant Genet Resour 16:315-324. https://doi.org/10.1017/ S1479262117000351

Long A, Zhang J, Yang LT, Ye X, Lai NW, Tan LL, Lin D, Chen LS (2017) Effects of low pH on photosynthesis, related physiological parameters, and nutrient profiles of citrus. Front Plant Sci 8:185. https://doi.org/10.3389/fpls.2017.00185

Mathur S, Mehta P, Jajoo A (2013) Effects of dual stress (high salt and high temperature) on the photochemical efficiency of wheat leaves (Triticum aestivum). Physiol Mol Biol Plants 19:179-188. https:// doi.org/10.1007/s12298-012-0151-5

Oukarroum A, El Madidi S, Schansker G, Strasser RJ (2007) Probing the responses of barley cultivars (Hordeum vulgare L.) by chlorophyll a fluorescence OLKJIP under drought stress and rewatering. Environ Exp Bot 60:438-446. https://doi.org/10.1016/j. envexpbot.2007.01.002

Outlaw WH, De Vlieghere-He X (2001) Transpiration rate. An important factor controlling the sucrose content of the guard cell apoplast of broad bean. Plant Physiol 126:1716-1724. https://doi. org/10.1104/pp.126.4.1716

Pantin F, Monnet F, Jannaud D, Costa JM, Renaud J, Muller B, Simonneau T, Genty B (2013) The dual effect of abscisic acid on stomata. New Phytol 197:65-72. https://doi.org/10.1111/nph.12013

Poudyal D, Rosenqvist E, Ottosen CO (2019) Phenotyping from lab to field-tomato lines screened for heat stress using Fv/Fm maintain high fruit yield during thermal stress in the field. Funct Plant Biol 46:44-55. https://doi.org/10.1071/FP17317

Qu M, Zheng G, Hamdani S, Essemine J, Song Q, Wang H, Chu C, Sirault X, Zhu XG (2017) Leaf photosynthetic parameters related 
to biomass accumulation in a global rice diversity survey. Plant Physiol 175:248-258. https://doi.org/10.1104/pp.17.00332

Rapacz M, Sasal M, Gut M (2011) Chlorophyll fluorescence-based studies of frost damage and the tolerance for cold-induced photoinhibition in freezing tolerance analysis of Triticale $(\times$ Triticosecale Wittmack). J Agron Crop Sci 197:378-389. https://doi. org/10.1111/j.1439-037X.2011.00472.x

Rapacz M, Sasal M, Kalaji HM, Kościelniak J (2015) Is the OJIP test a reliable indicator of winter hardiness and freezing tolerance of common wheat and triticale under variable winter environments? PLoS ONE. https://doi.org/10.1371/journal.pone.0134820

Rezaei Nejad A, Van Meeteren U (2008) Dynamics of adaptation of stomatal behaviour to moderate or high relative air humidity in Tradescantia virginiana. J Exp Bot 59:289-301. https://doi. org/10.1093/jxb/erm308

Rosales-Serna R, Ramirez-Vallejo P, Acosta-Gallegos JA, CastilloGonzález F, Kelly JD (2000) Grain yield and drought tolerance of common bean under field conditions. Agrociencia 34:153-165

Schaeffer R, Szklo AS, de Lucena AFP, Borba BSMC, Nogueira LPP, Fleming FP, Troccoli A, Harrison M, Boulahya MS (2012) Energy sector vulnerability to climate change: a review. Energy 38:1-12. https://doi.org/10.1016/j.energy.2011.11.056

Seifikalhor M, Hassani SB, Aliniaeifard S (2019) Seed priming by cyanobacteria (Spirulina platensis) and salep gum enhances tolerance of maize plant against cadmium toxicity. J Plant Growth Regul. https://doi.org/10.1007/s00344-019-10038-7

Sharma DK, Andersen SB, Ottosen CO, Rosenqvist E (2015) Wheat cultivars selected for high Fv/Fm under heat stress maintain high photosynthesis, total chlorophyll, stomatal conductance, transpiration and dry matter. Physiol Plant 153:284-298. https://doi. org/10.1111/ppl.12245

Shiferaw B, Baker DA (1996) An evaluation of drought screening techniques for Eragrostis tef. Tropical Science (United Kingdom)

Strasser RJ, Srivastava A, Tsimilli-Michael M (2000) The fluorescence transient as a tool to characterize and screen photosynthetic samples. Probing photosynthesis: mechanisms, regulation and adaptation, pp 445-483

Strauss AJ, Krüger GHJ, Strasser RJ, Van Heerden PDR (2006) Ranking of dark chilling tolerance in soybean genotypes probed by the chlorophyll a fluorescence transient OJIP. Environ Exp Bot 56:147-157. https://doi.org/10.1016/j.envexpbot.2005.01.011
Tamburino R, Vitale M, Ruggiero A, Sassi M, Sannino L, Arena S, Costa A, Batelli G, Zambrano N, Scaloni A, Grillo S (2017) Chloroplast proteome response to drought stress and recovery in tomato (Solanum lycopersicum L.). BMC Plant Biol 17:40. https ://doi.org/10.1186/s12870-017-0971-0

Taulavuori K, Taulavuori E, Sarjala T, Savonen EM, Pietiläinen P, Lähdesmäki P, Laine K (2000) In vivo chlorophyll fluorescence is not always a good indicator of cold hardiness. J Plant Physiol 157:227-229. https://doi.org/10.1016/S0176-1617(00)80195-9

Van Meeteren U, Kaiser E, Malcolm Matamoros P, Verdonk JC, Aliniaeifard S (2020) Is nitric oxide a critical key factor in ABAinduced stomatal closure? J Exp Bot 71:399-410. https://doi. org/10.1093/jxb/erz437

Xia J, Wishart DS (2016) Using MetaboAnalyst 3.0 for comprehensive metabolomics data analysis. Curr Protoc Bioinform 55:14-10. https://doi.org/10.1002/cpbi.11

Zhang J, Jiang XD, Li TL, Cao XJ (2014) Photosynthesis and ultrastructure of photosynthetic apparatus in tomato leaves under elevated temperature. Photosynthetica 52:430-436. https://doi. org/10.1007/s11099-014-0051-8

Zhou R, Yu X, Kjær KH, Rosenqvist E, Ottosen CO, Wu Z (2015) Screening and validation of tomato genotypes under heat stress using Fv/Fm to reveal the physiological mechanism of heat tolerance. Environ Exp Bot 118:1-11. https://doi.org/10.1016/j.envex pbot.2015.05.006

Zhou R, Yu X, Ottosen CO, Rosenqvist E, Zhao L, Wang Y, Yu W, Zhao T, Wu Z (2017) Drought stress had a predominant effect over heat stress on three tomato cultivars subjected to combined stress. BMC Plant Biol 17:24. https://doi.org/10.1186/s1287 0-017-0974-X

Živčák M, Brestič M, Olšovská K, Slamka P (2008) Performance index as a sensitive indicator of water stress in Triticum aestivum $\mathrm{L}$. Plant Soil Environ 54:133-139. https://doi.org/10.7221/392-PSE

Publisher's Note Springer Nature remains neutral with regard to jurisdictional claims in published maps and institutional affiliations. 